\title{
Estudo de caso: cisterna urbana, em Várzea do Poço, Bahia
}

\author{
ROCHA, André Azevedo ${ }^{1}$ \\ GNADLINGER, João \\ PALA, Terezinha ${ }^{3}$ \\ 1IRPAA - Instituto Regional da Pequena Agropecuária Apropriada, Juazeiro/BA, Brasil. andre@irpaa.org \\ 2IRPAA - Instituto Regional da Pequena Agropecuária Apropriada, Juazeiro/BA, Brasil. joao@irpaa.org \\ 3Sociedade do Divino Salvador, Comunidade Santa Clara, Várzea do Poço/BA, Brasil. terezinhapala@hotmail.com
}

\section{Resumo}

O estudo de caso mostra como famílias da zona urbana do município de Várzea do Poço, no Semiárido do Norte da Bahia, conseguem suprir o fornecimento de água para o consumo humano através de cisternas urbanas. $O$ abastecimento no centro e na periferia da cidade se dá através da rede de tubos, cuja água é oriunda da represa de São José do Jacuípe, com captação na comunidade de Barra Nova, tratada e fornecida pela EMBASA. Pela salinização da represa nos últimos anos a água tornou-se inapropriada para o consumo humano. Os moradores resgataram e aprimoraram técnicas de estocagem de água de chuva em cisternas como forma de resolver o problema da falta de água apta ao consumo humano e preparo de alimentos. As demais demandas domésticas continuam supridas pela rede pública de abastecimento. Um aspecto muito positivo é a diversificação de tamanho das cisternas, adequando-as à estrutura fundiária urbana local e ao tamanho das famílias. Um grupo de religiosas assessora a comunidade, mobilizando recursos, organizando as famílias, articulando parceiros, e auxiliando-as na formação de militância e na gestão de um fundo rotativo que permite estender o projeto a novas famílias continuamente.

Palavras-Chave: clima semiárido, abastecimento urbano, tecnologias sociais.

\section{Abstract}

The case study shows how families from the urban area of the municipality of Várzea do Poço, in the semi-arid North of Bahia, succeed in supplying water for human consumption through urban cisterns. The supply in the center and at the outskirts of the city occurs through the network of pipes, whose water comes from the São José do Jacuípe Dam, with capture in the community of Barra Nova, treated and supplied by EMBASA. Due to the salinization of the dam in recent years, the salt content is increasing, making water inappropriate for human consumption. The residents rescued and improved techniques for storing rainwater in cisterns as a way to solve the problem of lack of water suitable for human consumption and preparation of food. The remaining domestic demands continue to be achieved by the public water supply. A very positive aspect is the diversification of the size of the cisterns, adapting them to the local urban land structure and the size of the families. A group of religious advises the community, mobilizing resources, organizing families, articulating partners and assisting them in forming militancy and managing a revolving fund that allows extend the project to be extended continuously to new families.

Key-Words: semi-arid climate, urban water supply, social technologies. 


\section{Introdução}

O Brasil está incluído entre os países de maior reserva de água doce, ou seja, $13,8 \%$, do deflúvio médio mundial, com uma disponibilidade hídrica per capita variando de $1.835 \mathrm{~m}^{3} / \mathrm{hab} / \mathrm{ano}$ na bacia hidrográfica do Atlântico Leste, a $628.938 \mathrm{~m}^{3} / \mathrm{hab} / \mathrm{ano}$, na bacia Amazônica (Freitas et al., 1999). Porém devido às dimensões geográficas e diversidade climática, algumas regiões sofrem grave escassez de água, como o Semiárido brasileiro, tanto para consumo humano, como para o desenvolvimento socioeconômico. Apenas $3 \%$ do total de água existente no país se encontram na região Nordeste, sendo que $63 \%$ estão localizados na bacia hidrográfica do rio São Francisco e $15 \%$ na bacia do rio Parnaíba, que juntos detêm $78 \%$ da água na região. As bacias dos rios intermitentes detêm apenas $22 \%$ e concentram-se em 450 açudes de grande porte, cuja capacidade é superior a um milhão de metros cúbicos entre os mais de 70 mil existentes (Nascimento, et al., 2016).

A Região semiárida ocupa $56,5 \%$ da região Nordeste, com uma área de $980.133,079 \mathrm{~km}^{2}$ estendendose do estado do Piauí ao Norte de Minas Gerais perfazendo 1.135 municípios, com uma população de 22,5 milhões de pessoas ( $11,8 \%$ da população brasileira), destacando que 8,5 milhões (38\%) residem na zona rural (Brasil, 2012).

Como principais características climáticas destacam-se as temperaturas médias elevadas, a alta evapotranspiração (evaporação potencial de até $3.000 \mathrm{~mm} / \mathrm{ano}$ ) e precipitações médias anuais inferiores a $800 \mathrm{~mm}$, extremamente irregulares e concentradas, gerando os períodos de chuvas e estiagens: apenas três em cada dez anos são considerados normais quanto à distribuição das precipitações. Existe a característica de irregularidade na distribuição dessa chuva no tempo e no espaço geográfico.

Temos anualmente até oito meses de estiagem, sendo o volume de chuva muito variável ocasionando enchentes, mas também secas anuais e plurianuais no Semiárido. Considerando a seca como um fenômeno natural e cíclico, os técnicos Francisco Girardi e Luís Teixeira, do Centro Tecnológico da Aeronáutica (CTA) - São José dos Campos - SP, analisando o histórico pluviométrico, de 1849 em diante, observam que a mesma acontece com intensidade menor de $13 \mathrm{em} 13$ anos e com período mais prolongado de 26 em 26 anos (GIRARDI \& TEIXEIRA, 1978). Estas análises apontam para mais uma provável grande seca no período de 2031 a 2037, tal como foi prevista, a ocorrida recentemente de 2005 a 2011. Logo não se pode combater a seca, mas é possível defender-se de seus efeitos.

A ocorrência dessas grandes estiagens costuma causar graves problemas de insegurança hídrica e alimentar, provocando a migração de famílias, morte de animais e até de pessoas (Nascimento et al., 2016). Tratados como fatalidade ao longo da história, hoje boa parte desses efeitos vem sendo minimizados no meio rural, por famílias que conseguiram experimentar e adotar técnicas, métodos e hábitos compatíveis com as condições climáticas do lugar, processo denominado de "Convivência com o Semiárido".

A captação e estoque de água de chuva é um dos princípios da Convivência como o semiárido, e sendo a chuva, a fonte primária de toda água doce, apesar de suas limitações, variabilidade e imprevisibilidade, chega democrática e gratuitamente em todos os lugares, e por isso apresenta grande potencial para reduzir efeitos da escassez de água seja em volumes ou qualidade, frente às fontes secundárias, insuficientes, caras, poluídas ou em constantes colapsos.

Em revisão de literatura, denominada "Água de chuva no manejo integrado dos recursos hídricos em localidades semiáridas: Aspectos históricos, biofísicos, técnicos, econômicos e sociopolíticos", Gnadlinger faz memória de que as tecnologias dessa natureza são "...tão antigas quanto as montanhas”. O autor cita países como China, Índia, Irã, Israel, Jordânia e Sri Lanka, cujas práticas de captação e manejo da água de chuva, dentre outros métodos, por meio de cisternas, em diversos espaços e finalidades distintas, remota até 2.000 anos de existência. O certo desuso dessa estratégia 
em meados da história aos tempos modernos, é justificado por Gnadlinger, dentre outros fatores: pelas mudanças climáticas, em que precipitações cada vez mais escassas provocaram o colapso dos sistemas de captação deficitários; pelo crescimento populacional superior ao desenvolvimento dos sistemas de abastecimento, sobretudo com as invasões decorrentes dos processos de colonização; e introdução de modelos europeus de desenvolvimento baseados em tributos e capitais em vez de sistemas socio comunitários de manejo da água, seja para o abastecimentos de sítio, vilarejos e cidades, seja na agricultura e pecuária que mudou-se culturalmente para espécies menos adaptadas aos sistemas centenários, e onde megaprojetos de abastecimento de água (construção de grandes barragens, exploração de águas subterrâneas e projetos de irrigação que utilizam energia fóssil ou elétrica) foram objeto de maior ênfase (GNADLINGER, 2015).

No Brasil, apostando no estoque de água de chuva como forma de superação dos efeitos da seca, através do uso de cisternas domiciliares, cuja a água destina-se ao consumo humano e preparo de alimentos, entidades da sociedade civil vinculadas à Articulação Semiárido Brasileiro - ASA, iniciaram uma forte mobilização social que nos últimos 18 anos resultou na implementação de cerca de 1.200.000 unidades - cada reservatório de $16 \mathrm{~m} 3$ por família rural. Mais recentemente, há cerca de uma década, vêm sendo implementadas nas áreas rurais do Semiárido brasileiro por essa articulação (ASA), também tecnologias que possibilitam a captação, manejo e uso da água de chuva para produção de alimentos, por meio do Programa uma Terra e duas Águas (P1+2), que contempla não só cisternas, mas diversos reservatórios, tais como barreiros trincheiras, tanques de pedras, algumas com capacidade superior a $1.000 \mathrm{~m} 3$. O número de beneficiários do $\mathrm{P} 1+2$ é estimado em 200.000 famílias. A demanda que permanece é da ordem de 300 mil famílias à espera de cisterna para água de consumo humano, e de 600 mil aguardando uma tecnologia de água para produção.

Para IRPAA (2017), a falta de água, seja em quantidade, qualidade ou regularidade, deriva de um problema primário: falta de gestão das fontes, logo uma crise generalizada de gestão ambiental, aliada à ausência de política de convivência com o clima, se desdobra em constantes crises hídricas no semiárido. A captação e estoque de água de chuva é uma forma de minimizar a pressão sobre as fontes naturais e otimizar o uso da água no campo e na cidade. A viabilidade técnica e econômica da captação de água de chuva no meio urbano é confirmada por Santos, et al., (2015), que entre várias outras razões apontam o uso em "complementação da fonte de abastecimento" e "redução da conta de água".

Somente em 2017, vinte anos após criação da lei das águas (Lei $n^{\circ}$ 9.433/97), o Brasil incluiu nesta, o objetivo de "incentivar e promover a captação, a preservação e o aproveitamento de águas pluviais" (Lei $\left.n^{0} 13.501 / 2017\right)$. Nacionalmente, uma legislação que torna obrigatório o aproveitamento de água de chuva em prédios públicos ainda se encontra em discussão, e a única normativa existente, a NBR 15.527/2007 se limita ao aproveitamento de água de chuva em áreas urbanas para fins não potáveis, diferente de Japão, Austrália e Estados Unidos, por exemplo, em que a finalidade potável é regulamentada prevendo-se também o suprimento por água de chuva. Assim, o aproveitamento de água da chuva segue promovendo diversos benefícios à população brasileira, inclusive o suprimento de fins potáveis, mas, sem legislação específica vigente que trabalhe com esse tema e que estabeleça diretrizes para a sua melhor efetivação.

Embora, vista por muitos gestores como um problema, sobretudo nas cidades mal planejadas, em virtude dos efeitos causados pelos alagamentos, atualmente muitos se preocupam não somente o desenvolvimento e aperfeiçoamento de sistemas de drenagem de águas pluviais, mas também com o aproveitamento das águas que caem sobre os telhados residenciais ou de prédios públicos, a exemplo do município de llhéus, na Bahia, em que na tentativa de impulsionar essa cultura criou-se a Lei $\mathrm{N}^{\circ}$ 3.910, de 05 de março de 2018, que tornou obrigatória a captação e aproveitamento de água de chuva em prédios públicos daquela cidade. 
Apesar de praticada há um tempo inestimável, nos últimos anos vem sendo evidenciada a experiência de captação de água de chuva, especificamente em áreas urbanas do Semiárido brasileiro, por inciativa também da sociedade civil, e em algumas cidades baianas com apoio do poder público estadual. Essa prática é motivada pela escassez de água nesses espaços, seja em quantidade, regularidade ou qualidade para usos mais nobres como o alimentar.

No Piemonte da Chapada Diamantina, cidades expressivas como Capim Grosso e Jacobina fazem uso dessa tecnologia há décadas, e em Várzea do Poço, cidade da mesma região, famílias da zona urbana continuam adotando-a em virtude do elevado teor de sal presente na água servida pela rede pública, oriunda da represa de São José do Jacuípe, com captação na comunidade de Barra Nova, tratada e fornecida pela EMBASA (Empresa Baiana de Água e Saneamento).

De acordo com Fontes (2008), nos últimos anos, o teor de sais na represa São José do Jacuípe está aumentando (Figura 1), tornando a água cada vez mais inapropriada para o consumo humano. Assim os moradores resgataram e aprimoraram técnicas de estocagem de água de chuva em cisternas como forma de resolver o problema da falta de água apta para beber e preparar alimentos. As demais demandas domésticas continuam supridas pela rede pública de abastecimento.

Figura 1: Concentração de cloreto no reservatório de São José do Jacuípe (Fontes, 2008).

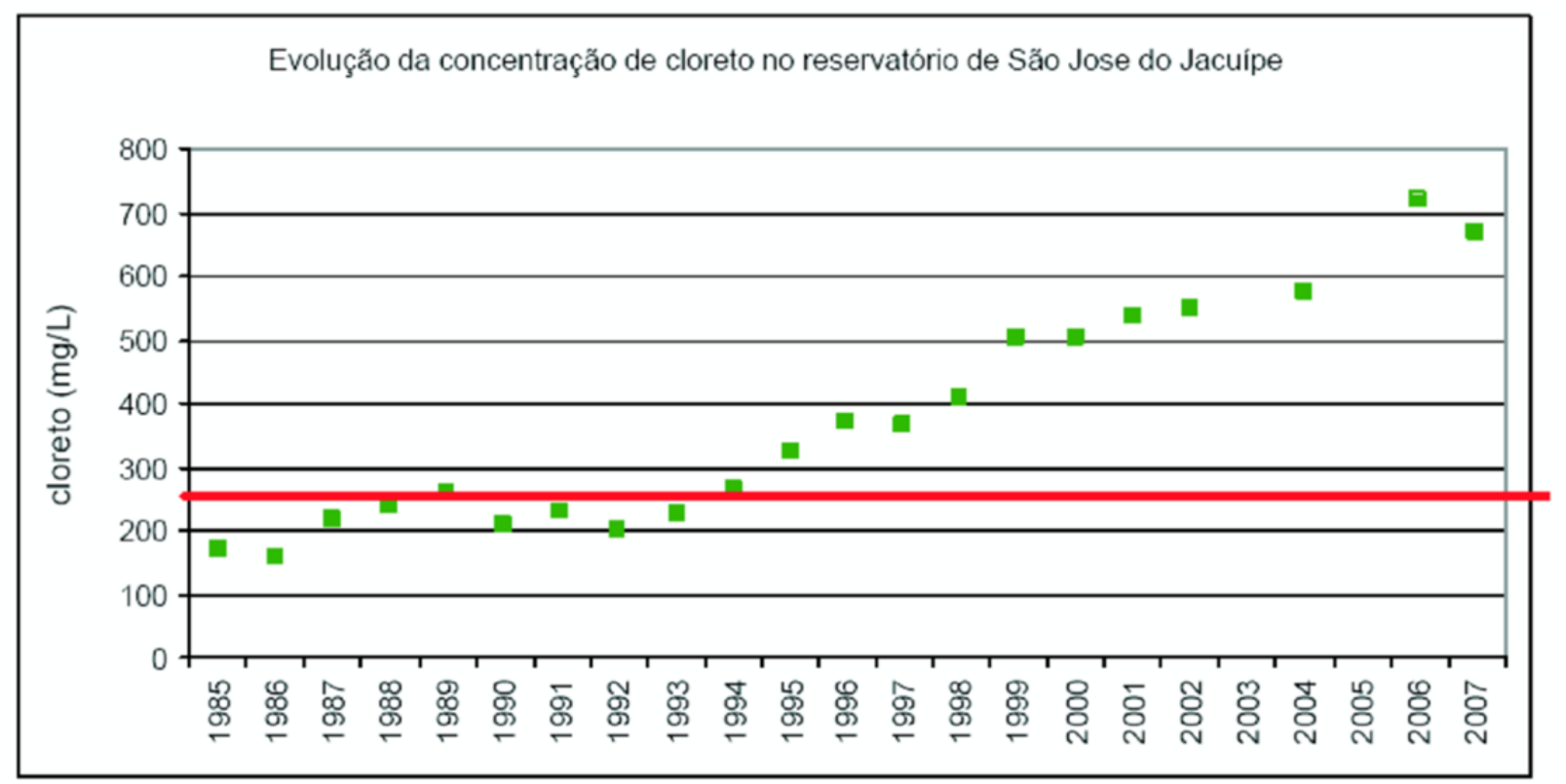

Fonte: Embasa (2002), BMA (2005) e Programa de Monitoramento

\section{Desenvolvimento}

\subsection{Metodologia}

Foram realizadas visitas (Figura 2) em residências que dispõem das cisternas, entrevistas com famílias que a utilizam e vários contatos presenciais e telefônicos com assessoras e pedreiro que contribuem na implementação dessas tecnologias. Também ocorreu uma reunião com lideranças na cidade, entre estas, missionária, assistente social, radialista, comerciantes e agricultores que moram na cidade de Várzea do Poço, no último trimestre de 2017.

As informações textuais, numéricas e fotográficas foram sistematizadas pelo autor deste artigo, primariamente em formato de relatório e socializado com a equipe do Instituto Regional da Pequena Agropecuária Apropriada - IRPAA, do qual é colaborador, bem como com as missionárias Salvatorianas lideradas por Terezinha Pala, que nos acolheram nas visitas, e posteriormente 
convertida ao presente trabalho.

Figura 2: Participantes de reunião com lideranças comunitárias de Várzea do Poço.

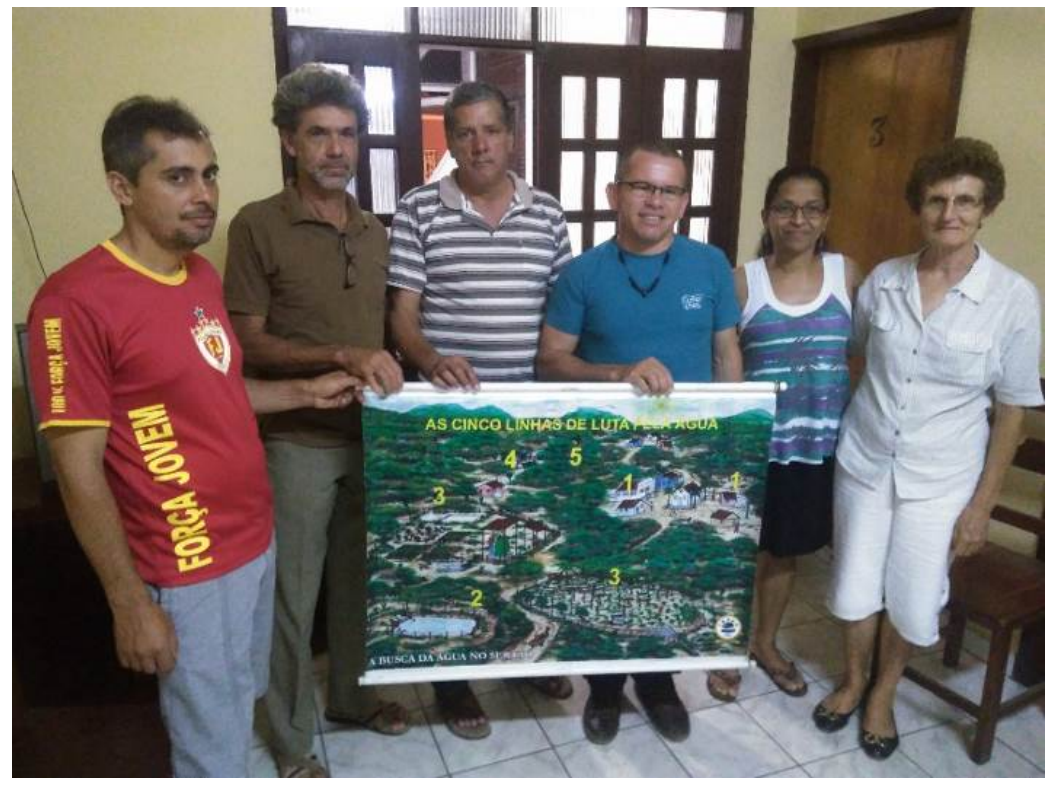

Fonte: ROCHA (Autor)

\subsection{Estado da arte}

\subsubsection{Status}

A portaria 2.914 de 12/12/2011 do Ministério da Saúde requer como padrão de qualidade da água para consumo humano, dentre outros parâmetros, o nível máximo de $250 \mathrm{mg} / \mathrm{L}$ para Cloreto (Brasil, 2011).

Estudos de órgãos que administram o reservatório de São José do Jacuípe, apontam aumento progressivo no nível de salinidade na água da mesma, variando com o tempo e volume de água disponível, cujo teor de cloreto vai de 200 a 700mg/L (Figura 1), distanciando muito do nível máximo aceitável pela legislação brasileira para água potável que é de $250 \mathrm{mg} / \mathrm{L}$.

Conhecendo a tecnologia social, cisternas de placas praticadas ao longo do tempo no Semiárido brasileiro como um todo, incluindo-se a cidade local, um grupo de religiosas passou a potencializar a ação fazendo assessoria à comunidade, mobilizando recursos, organizando as famílias, articulando parceiros e auxiliando-as na formação de militância e na gestão de um fundo rotativo que permite estender o projeto a novas famílias continuamente.

A água de chuva estocada nas cisternas é exclusiva à ingestão direta, via alimentos cozidos, ou na limpeza de alimentos que são consumidos crus. As demais demandas domésticas continuam supridas pela rede pública de abastecimento. Um aspecto muito positivo é a diversificação de tamanho das cisternas, adequando-as à estrutura fundiária urbana local e ao tamanho das famílias.

As cisternas (Figuras 3 e 4) são construídas em placas de cimento, contendo amarração de arames, em tamanhos diversos conforme a quantidade de pessoas que habitam a casa da família contemplada. É disposta superficialmente, sem risco de contaminação por fossas convencionais, presentes nas residências das famílias da cidade. Algumas casas têm altura insuficiente para instalação da cisterna e estrutura de filtração, requerendo adaptação da técnica para adequar as dimensões da cisterna de modo a não comprometer o escoamento por gravidade via calhas dispostas das extremidades dos telhados.

O material utilizado (Tabela 1) e a metodologia de construção é similar ao adotado em escala pela Articulação Semiárido Brasileiro, e avalizada pelo Ministério do Desenvolvimento Social conforme teor 
do anexo da Instrução Operacional SESAN № 02, de 08 de agosto de 2017 (Instrução regulamentada pela Lei $n^{\circ} 12.873$, de 24 de outubro de 2013, Decreto $n^{\circ} 8.038$, de 04 de julho de 2013 e Portaria $n^{\circ}$ 130, de 14 de novembro de 2013) (Brasil, 2017).

Quadro 1: Panorama da localização, método de construção das cisternas e dados do município.

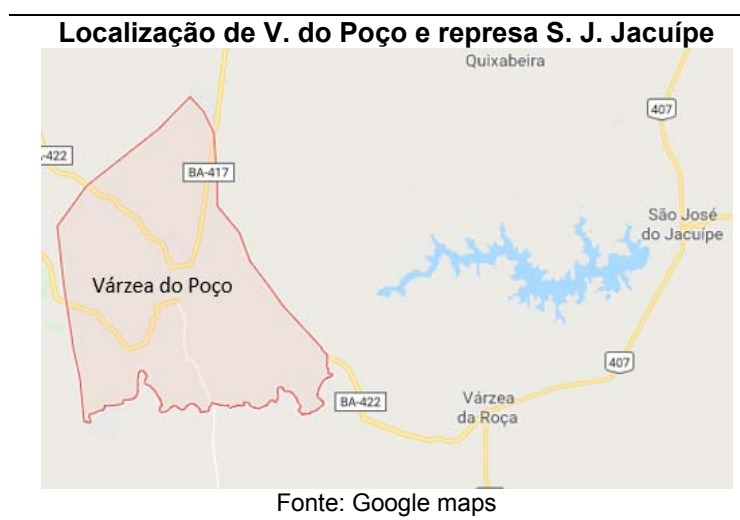

Fundo, vigas, placas de paredes e da tampa

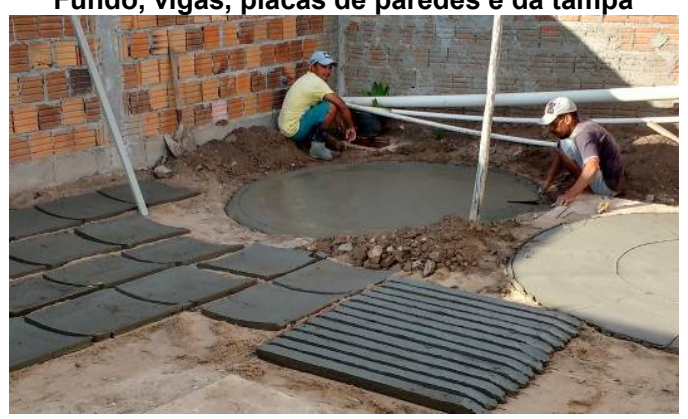

Fonte: PALA (Autora)

Acabamentos em argamassa

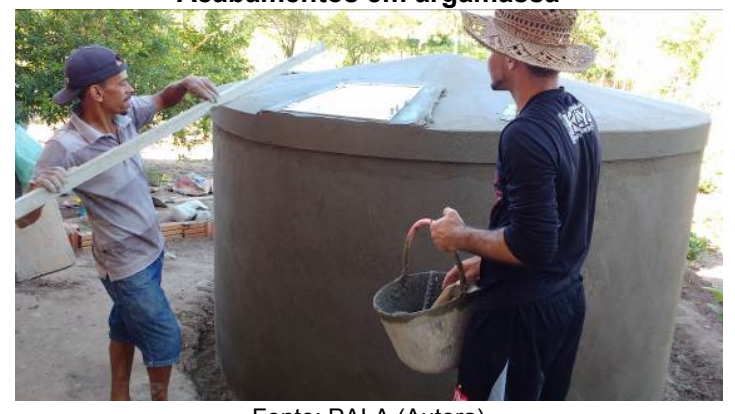

Fonte: PALA (Autora)

População municipal estimada (2018)

Área da unidade territorial (2017)

Densidade demográfica estimada (2018)

Salário médio mensal dos trabalhadores formais (2016)

Percentual da população $\mathrm{c} /$ rendimento mensal per capita de até $1 / 2$ salário mínimo (2010)

Taxa de escolarização de 6 a 14 anos de idade (2010) PIB per capita (2015)

Índice de Desenvolvimento Humano Municipal (IDHM) (2010)

Mortalidade Infantil (2014)

Internações por diarreia (2016)

Esgotamento sanitário adequado (2010)

Arborização de vias públicas (2010)

Urbanização de vias públicas (2010)
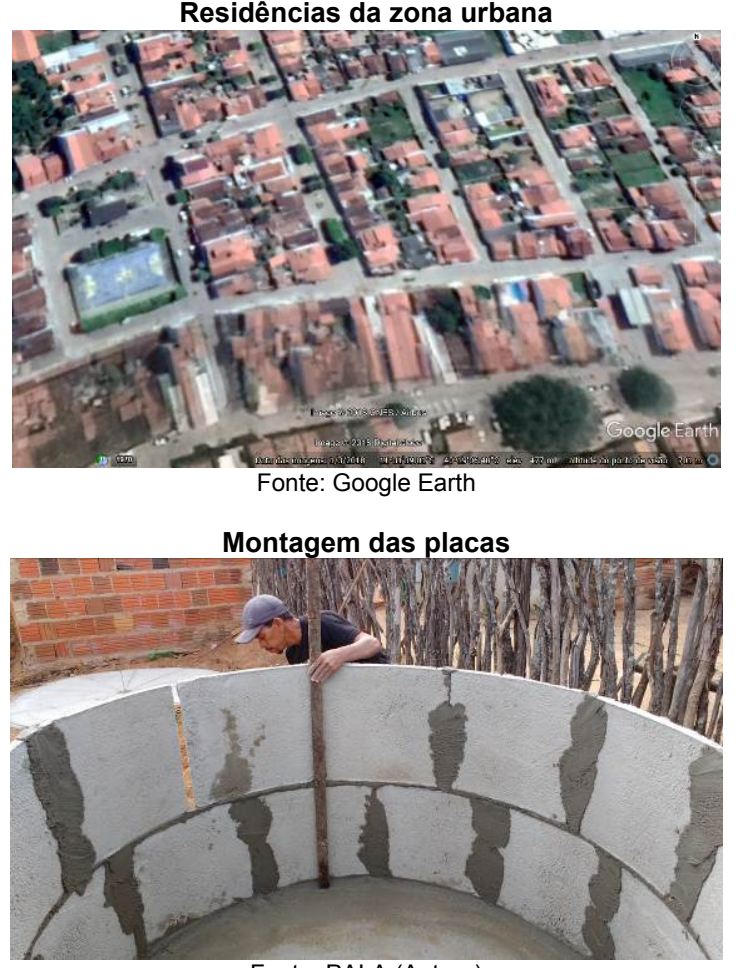

Fonte: PALA (Autora)

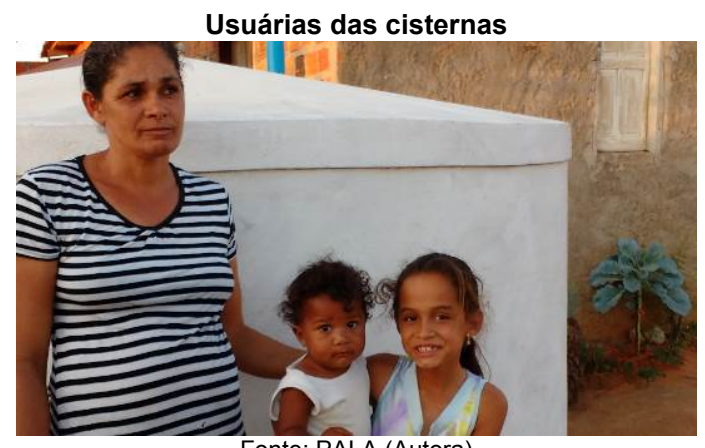

Fonte: PALA (Autora)

9.130 pessoas $206,478 \mathrm{~m}^{2}$

$44,22 \mathrm{hab} / \mathrm{km}^{2}$

1,7 salários mínimos

$51,4 \%$

$98,8 \%$

$\mathrm{R} \$ 7.230,18$

0.575

23,53 óbitos por mil nascidos vivos

4,1 internações por mil habitantes $20,3 \%$

$58,5 \%$

$4,7 \%$ 
Figura 3: Cisterna de $4 \mathrm{~m}^{3}$.

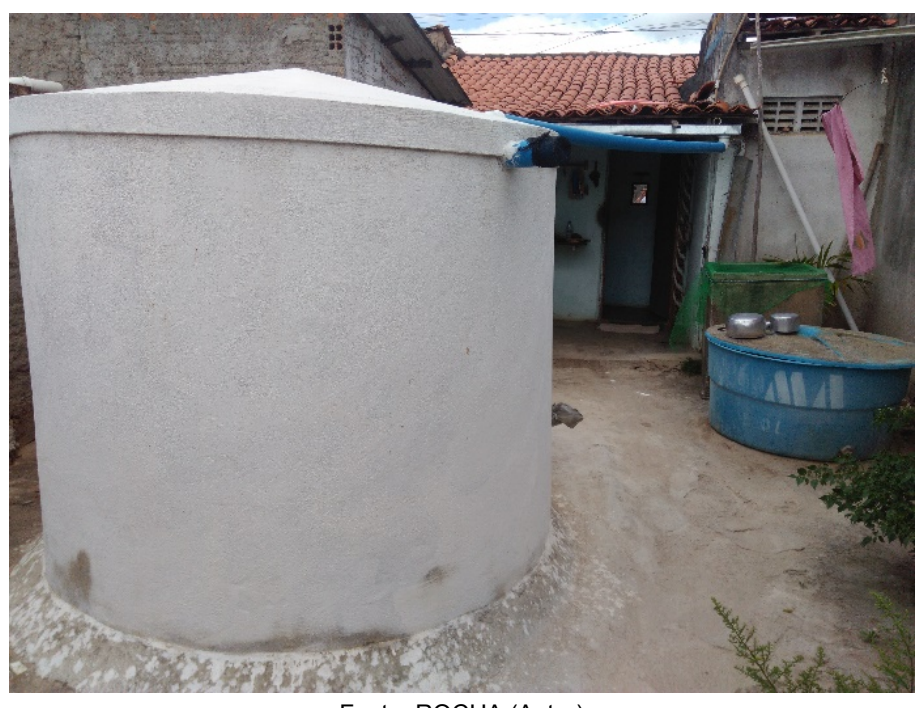

Fonte: ROCHA (Autor)

Figura 4: Disposição das cisternas nos quintais.

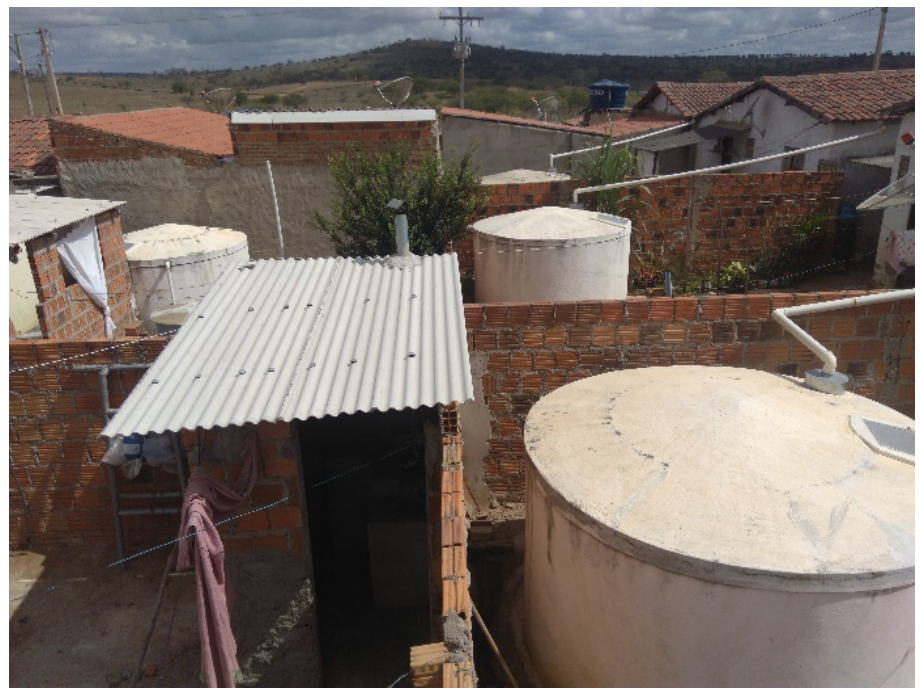

Fonte: ROCHA (Autor)

Tabela 1: Tipos de material utilizados/ recomendados na construção as cisternas urbanas.

\begin{tabular}{ll}
\hline Especificação & Unidade \\
\hline Cimento CPII - Z32 50kg & Saco \\
Vergalhão CA50 de $1 / 4(12 \mathrm{~m})$ & Barra \\
Arame Galvanizado $12-2,76 \mathrm{~mm}$ & $\mathrm{Kg}$ \\
Arame Galvanizado $18-1,24 \mathrm{~mm}$ & $\mathrm{Kg}$ \\
Impermeabilizante $3,6 \mathrm{~L}$ & Galão \\
Cal Refinado $5 \mathrm{~kg}$ & Pacote \\
Joelho $90^{\circ}$ Esgoto $75 \mathrm{~mm}$ & Peça \\
Tubo PVC Esgoto 75mm & Metro \\
Zinco Galvanizado 0,30m CH.28 & Metro \\
Massa Epóxi 100g & Caixa \\
Tela Nylon Mosquiteiro Verde & Metro \\
Bucha Plástica n. 05 & Peça \\
Parafuso Fenda 3,9 x19 Cabeça de Panela & Peça \\
Tubo PVC Esgoto 40mm & $\mathrm{cm}$ \\
Areia grossa lavada & $\mathrm{m}^{3}$ \\
Brita ${ }^{\circ} 01$ & $\mathrm{~m}^{3}$ \\
Tampa 60cm X650cm X 48cm em alumínio/zinco & Unidade \\
Filtro coador 16x17 em alumínio/zinco & Unidade \\
\hline
\end{tabular}

De acordo com o pedreiro Valdenilson Damasceno (Fiinho), um dos construtores das cisternas em 
Várzea do Poço, em alguns casos já foram feitas escavações de até $50 \mathrm{~cm}$ no solo para instalação da cisterna, em função da baixa altura dos telhados, o que não é recomendado, sob risco de contaminação por fossas sanitárias. O dimensionamento das cisternas está coerente com o volume almejado, com exceção das de seis mil litros que tem capacidade real apenas para 5.800 litros.

Tabela 2: Aspectos das cisternas trabalhadas pelas irmãs Salvatorianas.

\begin{tabular}{cccc}
\hline Volume potencial & Demanda de cimento & Custo médio & Valor a ser devolvido \\
\hline $8 \mathrm{~m}^{3}$ & $10 \mathrm{sc}$ & $\mathrm{R} \$ 1.100,00$ integral; & $\mathrm{R} \$ 400,00$ \\
$6 \mathrm{~m}^{3}$ & $08 \mathrm{sc}$ & e $\mathrm{R} \$ 900,00$, excluindo-se o & $\mathrm{R} \$ 300,00$ \\
$4 \mathrm{~m}^{3}$ & $06 \mathrm{sc}$ & custo com areia e servente. & $\mathrm{R} \$ 200,00$ \\
\hline $\begin{array}{l}\text { Obs.: O serviço ou aquisição de areia, bem como, serviço de ajudante de pedreiro é assumido pela família por ocasião } \\
\text { da construção. O valor devolvido contribui para beneficiar outras famílias. }\end{array}$
\end{tabular}

Considerando o conceito de tecnologia social como sendo "produtos, técnicas ou metodologias reaplicáveis, desenvolvidas na interação com a comunidade e que representem efetivas soluções de transformação social", as cisternas de placas de cimento, também denominadas de placas prémoldadas, foram reconhecidas como tal, pela Fundação Banco do Brasil, numa submissão do "Programa de Aplicação de Tecnologia Apropriada às Comunidades" (PATAC), instituição que também promove a sua difusão. Seu método construtivo envolve pedreiros das próprias localidades e a participação das famílias beneficiadas na execução dos serviços de escavação, aquisição e fornecimento de materiais acessíveis tal como areia e água para construção. Simples, de baixo custo e adaptável a qualquer região, o reservatório possibilita maior independência e autonomia às famílias no acesso à água, otimizando tempo e dinheiro, sobretudo no dia a dia das mulheres, principais encarregadas na busca e manejo de água nos lares brasileiros. O processo de construção envolve ainda momentos de troca de experiências e saberes diversos entre famílias beneficiárias e assessores dos programas, o que promove o empoderamento e eleva a autoestima das pessoas envolvidas (FBB, 2015).

\subsubsection{Perspectivas}

$\mathrm{Na}$ perspectiva de aprimoramento da técnica e melhorias do processo ao qual a mesma está envolvida, e na posição de assessor das famílias e organizações sociais, o Irpaa faz as seguintes considerações:

$\checkmark$ Tratando-se de áreas urbanas desprovidas de rede coletora de esgoto, é preciso eliminar o risco de contaminação por fossas, construindo a cisterna sempre sobre a superfície - nunca abaixo do nível do solo, e provida de impermeabilizante aplicado na massa de reboco da cisterna;

$\checkmark \quad$ Utilizar dispositivo de descarte dos primeiros milímetros automaticamente, assegurando melhor qualidade da água armazenada - um exemplo de dispositivo é o desviUFPE (https://www.youtube.com/watch?v=tgvv06essYs);

$\checkmark$ Considerar a demanda mínima de água para consumo humano e preparo de alimentos da ordem de 14 litros por pessoa ao dia (Silva, et al., 1984), o que corresponde a 3.360 litros de água por pessoa em 8 meses (tempo médio de duração da estiagem anual) (Tabela 3);

$\checkmark$ Relacionar área de captação (telhado) (Tabela 3) com o volume da cisterna de modo a garantir a completa recarga da cisterna com cerca de $450 \mathrm{~mm}$ de chuva anual;

$\checkmark$ Trabalhar mais e melhor o processo de formação e mobilização social para que a tecnologia possa compor políticas públicas que viabilizem seu acesso pela população;

$\checkmark$ Como toda e qualquer água destinada ao consumo humano, é indispensável o uso de filtros, sobre os quais neste caso recomenda-se o modelo brasileiro conhecido como "filtro de barro" 
ou filtro de cerâmica, de eficiência e eficácia elevada.

Tabela 3: Referências sugeridas para adequação do volume da cisterna e tamanho do telhado.

\begin{tabular}{ccc}
\hline $\begin{array}{c}\text { Número de pessoas que } \\
\text { moram na casa }\end{array}$ & $\begin{array}{c}\text { Volume ideal da Cisterna } \\
\text { (litros) }\end{array}$ & $\begin{array}{c}\text { Tamanho mínimo do Telhado de } \\
\text { captação }\left(\mathrm{m}^{2}\right)\end{array}$ \\
\hline 1 & 4.000 & 9,0 \\
2 & 7.000 & 16,0 \\
3 & 10.000 & 22,0 \\
4 & 14.000 & 31,0 \\
5 & 16.000 & 36,0 \\
\hline
\end{tabular}

\section{Considerações Finais}

Leva-se em conta que a construção e utilização das cisternas urbanas destinadas ao estoque de água de chuva em Várzea do Poço é uma prática no mínimo decenal, da população local, cuja água destinase apenas ao consumo humano e preparo de alimentos. As demais demandas domésticas são supridas pela rede pública de abastecimento por meio de tubulações e entre as caraterísticas da água tubular encontra-se o significativo teor de sais. Assim consideramos que as mesmas se constituem como uma tecnologia social de relevante importância àquela população. Um aspecto muito positivo é diversificação de tamanho adequando-se à estrutura fundiária urbana local e ao tamanho das famílias.

Esta iniciativa é um exemplo prático de como dar "um passo para a autonomia e resiliência hídrica do Brasil pela captação da água de chuva" como citam as "Recomendações do $11^{\circ}$ Simpósio Brasileiro de Captação e Manejo de Água de Chuva", o corrido em João Pessoa - PB, de 11 a 14 de novembro de 2018 (ABCMAC, 2018).

\section{Agradecimentos}

Agradecemos a agências nacionais e internacionais de fomento à inclusão social que apoiam a construção de cisternas no Brasil, bem como as organizações AP1MC e ABCMAC pela promoção da cultura de captação de água de chuva. Do mesmo modo agradecemos às comunidades de base pela capacidade de organização e mobilização na busca de soluções apropriadas para seus problemas e na luta por direitos fundamentais do ser humano, especialmente à água.

\section{Referências}

ABCMAC - Associação Brasileira de Captação e Manejo de Água de Chuva. Recomendações do $11^{\circ}$ Simpósio Brasileiro de Captação e Manejo de Água de Chuva. João Pessoa, PB, 2018. Disponível em: http://www.abcmac.org.br/files/downloads/recomendacoes_11SBCMAC_171240.pdf. Acesso em: 13/12/2018.

BRASIL - República Federativa do Brasil. Ministério do Desenvolvimento Social. Programa Nacional de Apoio à Captação de Água de Chuva e Outras Tecnologias Sociais de Acesso à Água. Modelo da tecnologia social de acesso à água $\mathrm{N}^{\circ} 01$ - Cisternas de placas de 16 mil litros. 2017. Disponível em: http://mds.gov.br/assuntos/seguranca-alimentar/acesso-a-agua-1/programa-cisternas. Acesso em: 13/12/2018.

BRASIL - República Federativa do Brasil. Ministério da Ciência, Tecnologia e Inovação (MCTI) Instituto Nacional do Semiárido (INSA). Sinopse do Censo Demográfico para o Semiárido Brasileiro. Campina Grande - PB, 2012. Disponível em: https://portal.insa.gov.br/acervo-livros/198-sinopse-docenso-demografico-para-o-semiarido-brasileiro. Acesso em13/12/2018. 
BRASIL - República Federativa do Brasil. Ministério do Planejamento, Orçamento e Gestão. Instituto Brasileiro de Geografia e Estatística (IBGE). Dados dos municípios. 2018. Disponível em: https://cidades.ibge.gov.br/brasil/ba/varzea-do-poco/panorama. Acesso em: 12/12/2018.

BRASIL - República Federativa do Brasil. Ministério da Saúde. Portaria № 2.914, de 12 de Dezembro de 2011. Disponível em:

http://bvsms.saude.gov.br/bvs/saudelegis/gm/2011/anexo/anexo_prt2914_12_12_2011.pdf. Acesso em: 04/08/2018.

FONTES, A. S. Vulnerabilidade à salinização das águas superficiais da bacia do rio Jacuípe por meio de traçadores ambientais. Tese de Doutorado, Curso de Pós-graduação em geofísica da Universidade Federal da Bahia. 193 p. Salvador, 2008. Disponível em: https://repositorio.ufba.br/ri/handle/ri/7613. Acesso em: 04/08/2018.

FBB - FUNDAÇÃO BANCO DO BRASIL. Banco de Tecnologias Sociais. Cisternas de Placas Prémoldadas. 2015. Disponível em: http://tecnologiasocial.fbb.org.br/tecnologiasocial/banco-detecnologias-sociais/pesquisar-tecnologias/cisternas-de-placas-pre-moldadas.htm. Acesso em: $13 / 12 / 2018$.

GIRARDI, C \& TEIXEIRA, L., Prognóstico de Tempo a longa prazo, Relatório Técnico. ECA-06/78. CTA/IAE. São José dos Campos, SP, 1978.

GNADLINGER, J. Água de Chuva no Manejo Integrado dos Recursos Hídricos em Localidades Semiáridas: Aspectos Históricos, Biofísicos, Técnicos, Econômicos e Sociopolíticos. Em: SANTOS, D. B. dos et al. Captação, manejo e uso de água de chuva. INSA, Campina Grande, PB, 1975. ISBN 97885-64265-13-4. Disponível em: https://irpaa.org/fotos/file/gnadlinger_captacao_chuva_compressed.pdf

IRPAA - Instituto Regional da Pequena Agropecuária Apropriada. Água da Escola no Semiárido: Acesso, Gestão e Contextualização - $1^{\text {a }}$ Edição, 37f. Papel. 24x23cm. Juazeiro, Bahia, 2017. ISBN: 978-85-88104-05-1. Disponível em:

https://my.pcloud.com/publink/show?code=XZBepR7ZfFVFvCAd42Q5ulSiCOGg350sY1Rk. Acesso em: 04/08/2018.

NASCIMENTO, D. dos S.; MENEZES, A. de S.; ROCHA, A. A.; GNADLINGER, J. As Cinco Linhas de Abastecimento de Água na Comunidade de Cachoeirinha. Belém, PA, 2016. 10 Simpósio Brasileiro de Captação e Manejo de Água de Chuva. Disponível em: http://10sbcmac.ufpa.br/anais/ARQUIVOS/GT21-34-20161120154353.pdf. Acesso em: 03/08/2018.

SILVA, A. de S. PORTO, E. R.; LIMA, L. T.; GOMES, P. C. F. Cisternas Rurais: captação e conservação de água de chuva para consumo humano, dimensionamento, construção e manejo. Petrolina, PE: EMBRAPA-CPATSA: SUDENE, 1984. (EMBRAPACPATSA. Circular Técnica,12). 